\title{
1 A specialized deceptive pollination system based on elaborate mushroom \\ 2 mimicry
}

3

4 Satoshi Kakishima ${ }^{1}$, Nobuko Tuno ${ }^{2}$, Kentaro Hosaka ${ }^{1}$, Tomoko Okamoto ${ }^{3}$, Takuro Ito ${ }^{1}$, and Yudai Okuyama ${ }^{1 *}$ 5

6 1. Tsukuba Botanical Garden, National Museum of Nature and Science, Amakubo 4-1-1, Tsukuba, Ibaraki, 305-

7 0005, Japan

8 2. Laboratory of Ecology, Graduate School of Natural Science and Technology, Kanazawa University, Kanazawa 9 920-1192, Japan.

10 3. Laboratory of Insect Ecology, Faculty of Applied Biological Sciences, Gifu University, Yanagido 1-1, Gifu 501-

11 1193, Japan

12

13 *Author for correspondence: Yudai Okuyama

14 e-mail: yokuyama@kahaku.go.jp

15 phone: +81-29-853-8435 


\section{Abstract}

Despite its potential effectiveness for outcrossing, few examples of pollination via mushroom mimicry have been reported. This may be because the conditions under which the strategy can evolve are limited and/or because demonstrating it is challenging. Arisaema is a plant genus that has been suggested to adopt mushroom mimicry for pollination, although no compelling evidence for this has yet been demonstrated. Here, we report that Arisaema sikokianum utilizes mostly a single genus of obligate mycophagous flies (Mycodrosophila) as pollinators, and that the insect community dominated by Mycodrosophila is strikingly similar to those found on some species of wood-decaying fungi. Comparative chemical analyses of Arisaema spp. and various mushrooms further revealed that only A. sikokianum emits a set of volatile compounds shared with some mushroom species utilized by Mycodrosophila. Meanwhile, other closely related and often sympatric Arisaema species do not possess such typical traits of mushroom mimicry or attract Mycodrosophila, thereby likely achieving substantial reproductive isolation from A. sikokianum. Our finding indicates that mushroom mimicry is an exceptional and derived state in the genus Arisaema, thus providing an unprecedented opportunity to study the mechanisms underlying the coordinated acquisition of mimicry traits that occurred during a recent speciation event. 
61 The diversity of floral forms found in angiosperms reflects the diverse plant-pollinator interactions that flowers

62 engage in, wherein a particular suite of floral traits adapted to a specific functional group of pollinators is termed

63 'pollination syndrome' (Fenster et al. 2000, Ollerton et al. 2009). Among such relationships, a non-negligible

64 proportion (associated with 7500 plant spp.) are based on deceptive pollination strategies (Renner 2006), in which

65 plants lure pollinators by mimicking signals of food, mates or breeding sites without providing a reward to the

66 pollinators. Although deceptive systems are generally considered ineffective at attracting pollinators compared with

67 rewarding systems (Jersáková et al. 2006), the use of animal communities that are not otherwise involved in

68 pollination may be advantageous because it allows escape from the ecological constraint of pollinator availability in

69 time and space, as discussed in the context of the evolution of abiotic pollination (Cox 1991, Culley et al. 2002).

70 Moreover, it may reduce the likelihood of heterospecific pollen transfer, as plants may trade pollinator visitation

71 frequency for specificity (Scopece et al. 2010).

72 Mycophagous insects are rarely involved in pollination but are abundant in shady forest floor ecosystems, which

73 in turn are relatively devoid of flower-visiting insects (Policha et al. 2016). Nevertheless, few examples of

74 pollination via mushroom mimicry have been reported (Vogel 1978, Johnson and Schiestl 2016, Suetsugu 2018),

75 and the well-established example of pollination by mycophagous insects via mushroom mimicry is limited to the

76 orchid genus Dracula, in which mycophagous drosophilids are attracted to flowers that morphologically and

77 chemically resemble mushrooms (Endara et al. 2010, Policha et al. 2016, 2019).

78 The rare occurrence of mushroom mimicry as a pollination system may indicate that the conditions under which

79 the strategy can evolve are limited. For example, it may be because targeting specific groups of insects as pollinators

80 is difficult, as most mycophagous insects have broad host ranges owing to the ephemeral nature of the fungi they

81 feed on (Lacy 1984, Hanski 1989, but see Jonsell and Nordlander 2004). Moreover, demonstrating mushroom

82 mimicry is often challenging, given that the floral traits associated with mushroom mimicry are not well understood,

83 and the life histories of potentially mycophagous insects are largely unexplored.

84 In the present study, we explored an unverified example of specialized pollination via mushroom mimicry in an

85 aroid species, Arisaema sikokianum Franch. et Sav., although its striking morphological similarities to mushrooms

86 have long been recognized (see Figure 1a) (Vogel and Martens, 2000). Arisaema (Araceae) consists of 200 spp.,

87 with its center of diversity in E. Asia (Murata et al. 2018). The genus is well known for its 'one-way traffic'

88 mechanism, with most members being sequential hermaphrodites (Vogel and Martens, 2000), in which the spathe

89 functions as a trap for the pollinators (typically dipterans). Only male inflorescences have an exit hole at the bottom

90 of the spathe, and pollinators are trapped in the spathes of the female inflorescence, which does not have an exit,

91 after its pollination. Because mushroom-associated insects such as fungus gnats pollinate some Arisaema species,

92 mushroom mimicry has been suggested as their attraction mechanism (Vogel, 1978; Vogel and Martens, 2000).

93 However, such mimicry has not been demonstrated conclusively, and most species in the genus do not have

94 morphological or chemical characteristics shared with mushrooms.

95 Here, we show that although not all Arisaema species have 'mushroom flowers', A. sikokianum has specialized

96 floral traits for mushroom mimicry. To test the 'mushroom flower' hypothesis in A. sikokianum, we surveyed the

97 pollinators trapped within the inflorescences and compared them with the insects attracted to various mushrooms.

98 We further conducted comparative chemical analyses of floral and fungal volatile compounds to determine whether 
A. sikokianum imitates a specific fungus. Finally, we investigated whether the mushroom mimicry in A. sikokianum results in a unique pollination mode that enables reproductive isolation from other sympatric Arisaema species.

\section{Materials and Methods}

\section{Target plants}

Arisaema sikokianum is a tuberous perennial species endemic to western Japan and is ranked as vulnerable in the Red List of Japan (Ministry of the Environment, Government of Japan, 2012). This species is fairly rare across most of its distribution range and is ranked as highly endangered in most local (prefectural) red lists. However, the species is relatively abundant in Tokushima and Kochi prefectures. In mid to late April, the plant bears an inflorescence with a white, balloon-like appendix surrounded by a spathe that is white on the inside and dark purple on the outside (Figure 1a). As in most Arisaema spp., the inflorescence of A. sikokianum is unisexual, and the plant changes sex according to tuber size; larger tubers bear female inflorescences and smaller tubers male inflorescences (i.e., sequential hermaphroditism; Fukai, 2004). Male and female plants have almost identical inflorescences, except that a slit opening is present at the bottom of the inflorescence only in males, and the arrangement of the inflorescence tends to be higher in females. Arisaema japonicum Blume is closely related to A. sikokianum and belongs to the same section (Pistillata) (Ohi-Toma et al. 2016). The distribution ranges of A. japonicum and A. sikokianum overlap (Murata et al. 2018), and the two species sometimes exist sympatrically and bloom almost simultaneously. Arisaema japonicum has a similar growth habitat and ecology to A. sikokianum but is strikingly different in its floral characters, in that the inflorescence has a green, rod-shaped appendix surrounded by a green spathe (Figure 1b).

\section{Insect collection}

We field-collected flower visitors trapped inside the spathe of the female inflorescence of $>27$ individuals of $A$. sikokianum from six locations during April 20-22, 2016 (sites 1-6; Figure 2; Table S1). Over the following years (2017-2018), we conducted additional field collections of flower visitors from the inflorescences of 6 female and 20 male individuals of $A$. sikokianum during April 23-25, 2017, and from the inflorescences of 4 female and 21 male individuals of A. sikokianum during April 18-20, 2018 at study sites 1 and 2 (Table S2). To collect flower visitors from the male inflorescences, the exit hole was plugged with cotton, and insect visits were allowed for 1-2 days. This experiment also enabled us to measure the daily flower visitation rates. Although it is difficult to discriminate the principal pollinators from other flower visitors in Arisaema spp., flower visitors that exit the male spathe are inevitably covered with pollen grains (Figure 1c) due to the structure of the inflorescence they must pass through. Accordingly, we identified the principal pollinators according to the following criteria: first, the insect species should visit both male and female inflorescences with substantial frequency; second, the insect should be small enough to pass through the exit hole of the male inflorescence; and finally, the insect should be large enough to carry a sufficient amount of pollen on its body.

To examine the role of the mushroom-like appendix of A. sikokianum in attracting pollinators, the swollen top half of the appendix was removed using scissors for 15 male individuals on April 23, 2017, and for 30 male individuals on April 11 and 12,2019, at study sites 1 and 2. The bottom half of the appendix was left unremoved as it likely functions as a guard against insects escaping from the top of the spathe. The number of insect visits per day 
per inflorescence during the study period was compared between male individuals with a removed appendix $(\mathrm{N}=$ 45) and those with an intact appendix $(\mathrm{N}=42)$.

To assess the presence of pollinator isolation, we also collected flower visitors from A.japonicum co-flowering with $A$. sikokianum at the same study sites. For A. japonicum, we collected insects from the inflorescences of 7 female individuals in 2016, 16 female individuals and 37 male individuals in 2017, and 15 female individuals and 34 male individuals in 2018 at sites 1 and 2 (Table S2).

Insects collected from the Arisaema plants were identified both morphologically and by DNA sequencing of a 710-bp fragment of the mitochondrial cytochrome c oxidase subunit I gene using a method described previously (Okuyama et al. 2018). All newly generated DNA sequences are deposited in the DNA Data Bank of Japan (DDBJ) under accession nos. LC193971-194126.

One of the authors (NT) extensively collected insects visiting the mushrooms at the Kyoto University Botanical Garden (Figure 2) and has reported the visitation pattern previously (Tuno, 2001). Thus, we reanalyzed the original data from that report (Tuno, 2001) to compare the insect communities on mushrooms and Arisaema inflorescences. In Tuno (2001), only mushroom-visiting dipterans were included in the analysis, and the species groups (an informal taxonomic rank narrower than a subgenus that is traditionally used in drosophilid taxonomy; O'Grady and DeSalle, 2018) rather than the individual species were used as the categories for analyses. We followed the same categorization scheme, but coleopterans and other insects were also included in the analysis. Coleopterans and other insects were each grouped into a single category because they represented only a minor portion $(<10 \%)$ of the visitors to Arisaema inflorescences (see Results).

\section{Chemical analysis}

We collected volatiles from Arisaema inflorescences or mushrooms using solid phase microextraction (SPME) headspace sampling with 50/30 $\mu \mathrm{m}$ divinylbenzene/carboxene/polydimethylsiloxane fibers (Supelco/SigmaAldrich, Bellefonte, PA, USA). Data on volatile composition obtained using SPME under standardized sampling conditions are highly repeatable, and comparable with absorbent-based trapping methods not only for assessing quality but also for quantity (e.g., Povolo and Contarini 2003, Friberg et al. 2013). Indeed, the volatile profiles of multiple individuals of $A$. sikokianum and $A$.japonicum sampled across different years were consistent (see Results), indicating that our results regarding the chemical similarity of volatiles emitted from $A$. sikokianum inflorescences and mushrooms is unlikely to be affected by the sampling method used; i.e., SPME vs. absorbent-based.

For Arisaema spp., the plants used for volatile sampling were collected from their native populations (nine $A$. sikokianum plants from four localities and eight $A$. japonicum plants from four localities, and one to four plants each of other Arisaema species) and were cultivated in the nursery in Tsukuba Botanical Garden for 0.5-3 years until the volatile sampling (Table S3). Fully open inflorescences were cut from a potted individual and immediately enclosed in a 500-mL or 1-L glass beaker capped with aluminium foil, and the SPME fiber was exposed to the headspace for $30 \mathrm{~min}$. To clarify which parts of the inflorescences were responsible for the emission of volatiles in A. sikokianum, volatiles from the spathe, appendix and flower cluster were sampled separately by dissecting the inflorescence of a single $A$. sikokianum plant. For mushrooms, 30 fruiting bodies from 27 basidiomycous fungal species were collected, brought to the laboratory in Tsukuba Botanical Garden, and kept for $<2$ days until the analysis (Table S4). Although these fungal species were sampled from the distribution area of $A$. sikokianum, they were selected because 
they are common species in the secondary deciduous forests of Japan where A. sikokianum and other Arisaema

177 species grow. We aimed to sample a similar list of species to those studied in Tuno (2001), although our sample set

178 was not identical due to the difficulty of comprehensively collecting these fungal species as well as uncertainty in the

179 identification of some fungal species in Tuno (2001). The peak timing of fruiting body production varies among the

180 fungal species sampled, but the majority are capable of producing fruiting bodies during the flowering season of

181 Arisaema spp. (April-May, see Table S4). Each of the collected fruiting bodies was placed in a glass container of the appropriate volume (a 100-mL vial or a 500-mL or 1-L beaker). The ambient air of the sampling room was also analyzed several times during the sampling period to distinguish the volatiles emitted from the Arisaema plants or mushrooms. The sampled SPME fiber was analyzed immediately by gas chromatography-mass spectrometry. We used a GCMS-QP2010SE system (Shimadzu, Kyoto, Japan) equipped with an Rtx-5SilMS capillary column (30 m $\times 0.25 \mathrm{~mm}$; film thickness, $250 \mathrm{~nm}$; Restek, Bellefonte, PA, USA). Helium was used as the carrier gas at a velocity of $48.1 \mathrm{~cm} / \mathrm{s}$, and the injector temperature was $250^{\circ} \mathrm{C}$. The injector was operated in the splitless mode for $1 \mathrm{~min}$. Electron ionization mass spectra were obtained at a source temperature of $200^{\circ} \mathrm{C}$. The oven temperature was programmed to the following sequence: $40^{\circ} \mathrm{C}$ for $5 \mathrm{~min}$, followed by an increase to $220^{\circ} \mathrm{C}$ at $5^{\circ} \mathrm{C} / \mathrm{min}$ and then $280^{\circ} \mathrm{C}$ at $15^{\circ} \mathrm{C} / \mathrm{min}$, at which the oven was held for $5 \mathrm{~min}$.

For every volatile compound, the retention index was calculated using n-alkane (C6-C20) standards. Then, identification was carried out by comparison with the mass spectra in the NIST14 and NIST14s libraries and retention indices reported in the NIST Chemistry WebBook (Linstrom and Mallard 2001). Where possible, we further verified the identity of these compounds by comparing the mass spectra and the retention indices of the corresponding commercially available authentic compounds (purchased from Wako Pure Chemicals [Tokyo, Japan], Tokyo Chemical Industries [Tokyo, Japan], or Supelco/Sigma-Aldrich [Bellefonte, PA, USA]).

\section{Data analysis}

199 To characterize the volatile profiles of the individual samples, the peak area of the total ion chromatogram was used. Samples with no detectable volatile compounds were removed from the analysis. The composition of each compound within a sample was scored by the relative peak area (percentage) to calculate the Bray-Curtis dissimilarity among the samples, and then nonmetric multidimensional scaling was performed to compare the volatile profiles among samples using the R packages vegan (Oksanen et al. 2016) and MASS (Venables and Ripley 2002). The compositions of the insects collected from Arisaema inflorescences and mushrooms were also analyzed using similar procedures.

206 To evaluate the effect of removing the swollen top half of the $A$. sikokianum appendix on the insect visitation rate, 207 we used a generalized linear mixed model (glmer in the R package lme4) (Bates et al. 2015) using a Poisson error 208 distribution and log link function. We fitted "treatment" as a fixed term and "years", "populations" and "the length of survey periods" as random terms in the generalized linear mixed model.

210

\section{Results}

212 Insect assemblages attracted to A. sikokianum, A. japonicum and fungal fruiting bodies

213 In the three consecutive study years (2016-2018), we collected and identified a total of 266 and 101 insect visitors

214 from female and male inflorescences of $A$. sikokianum, respectively, and 83 and 68 insect visitors from female and 
male inflorescences of A. japonicum, respectively. On average, 1.42 and 1.14 insect individuals visited per one male inflorescence of $A$. sikokianum per day, whereas 0.30 and 0.72 insect individuals visited per one male inflorescence of A.japonicum per day during the study periods in 2017 and 2018, respectively (Table 1). The removal of the swollen top of the appendix from the male $A$. sikokianum inflorescence resulted in a significant decrease in insect visits $(\mathrm{N}=87, \mathrm{Z}=2.885, \mathrm{df}=82, \mathrm{P}=0.004$, two-tailed): 0.82 and 1.51 insect individuals visited each male inflorescence per day in the treatment and control groups, respectively (Table 2).

The composition of insect visitors found in the inflorescences differed strikingly between $A$. sikokianum and $A$. japonicum (Figure 3a). In A. sikokianum, 64.4-93.4\% of the insect visitors were drosophilid flies (Figure 1c-e, Table S5). In particular, Mycodrosophila spp. accounted for $66.7 \%$ of the total visitors, of which the most abundant species was Mycodrosophila gratiosa, accounting for $37.2 \%$ of the total visits. The insect visitors to the inflorescences of A. sikokianum with the appendix removed were also dominated by Mycodrosophila, which accounted for $76.3 \%$ of the total visits. Meanwhile, in A. japonicum, Sciaridae (26.0\%), Cecidomyidae (20.0\%), and Mycetophilidae (14.7\%) were the main insect visitors, while only one drosophilid individual, which was a species that has never been collected previously from the A. sikokianum spathe, was collected (Table S5). Accordingly, there was little overlap in pollinator assemblages between A. sikokianum and A.japonicum.

The insect assemblages trapped inside the inflorescences of $A$. sikokianum were strikingly similar to those attracted to the fruiting bodies of mushrooms, especially those of wood-decaying polyporous fungi (Figure $3 b$ ). We found that the level of dissimilarity of the compositions of attracted insects was much lower between $A$. sikokianum inflorescences and mushrooms ( $0.13-1.00,0.61$ on average) compared with between $A$. japonicum and mushrooms ( $0.61-1.00,0.89$ on average) or between A. sikokianum and A.japonicum ( $0.77-0.99,0.88$ on average). nine A. sikokianum individuals (Table S6). Fifteen compounds were common among the samples. The common volatiles consisted of monoterpenes, sesquiterpenes, benzyl nitrile, 2-ethylhexyl acetate and C8 aliphatics. Benzyl nitrile and one of the $\mathrm{C} 8$ aliphatics, 3-octanone, were the most abundant, comprising $0.2-39.4 \%$ and $12.9-40.7 \%$ of the total peak area of the volatiles detected, respectively (Figure $4 a$; Tables 3 and S6). Arisaema sikokianum has a showy white appendix that resembles a fungal fruiting body (mushroom). We confirmed that the mushroom-like appendix emits a major portion of the volatiles detected from the inflorescence, although the spathe had a similar volatile profile (Figure S1).

We detected a total of 21 volatile compounds (5-13 compounds per sample) from eight $A$. japonicum individuals, 12 of which were monoterpenes (Table S6). Only $\alpha$-pinene and limonene were common among the samples. The C8 aliphatics were rarely detected among the volatiles from A. japonicum, with the exception of two plants that emitted very small amounts of either 1,3-octadiene or 3-octanol. We further detected a total of 26 volatile compounds ( $0-17$ compounds per sample) from 7 additional Arisaema species that are potentially sympatric with $A$. sikokianum, 15 of which were monoterpenes and none of which were C8 aliphatics (Table S6).

To examine whether Arisaema inflorescences chemically mimic mushrooms, we sampled volatiles from the headspace of 27 species of mushrooms and detected a total of 147 volatile compounds ( $4-43$ compounds per sample; Table S6). Again, the compounds consisted mainly of monoterpenes, sesquiterpenes and C8 aliphatics. 
Only 3-octanone was common among all samples, and other C8 aliphatics (e.g. 1-octene, 1-octene-3-ol, 1-octene-3one and 3-octanol) were common among the majority of the samples. Meanwhile, monoterpenes and sesquiterpenes were more variable and rarely common among the samples. Among these terpenoids, only a sesquiterpene $\beta$ barbatene was shared among $>30 \%$ of the samples (10 fungal species), although the compound was not detected in the Arisaema samples.

To quantify the similarity of the volatile compositions from the Arisaema inflorescences and fungal fruiting bodies, we performed a nonmetric multidimensional scaling analysis based on Bray-Curtis dissimilarity calculated from a relative volatile composition matrix for each sample. We found that the level of dissimilarity of volatile compositions between $A$. sikokianum inflorescences and mushrooms $(0.54-0.97,0.81$ on average) was generally lower than that between the other Arisaema spp. and mushrooms ( $0.83-1.00,0.99$ on average) or between $A$. sikokianum and the other Arisaema spp. (0.91-1.00, 0.97 on average). Accordingly, the volatile profiles of $A$. sikokianum were plotted close to those of the mushrooms, whereas those of A. japonicum and the other Arisaema spp. were plotted distantly to both A. sikokianum and the mushrooms (Figure 4c).

\section{Discussion}

\section{Pollination via mushroom mimicry in A. sikokianum}

270 The present study was motivated by a finding of one of the authors (YO) during the management of the plant

271 collection in Tsukuba Botanical Garden; namely, that the inflorescence of A. sikokianum has a strong characteristic

272 fragrance reminiscent of mushrooms. The striking morphological similarity of $A$. sikokianum to certain mushrooms,

273 such as the young fruiting body of the bracket fungus Ganoderma applanatum (Pers.) Pat, suggests that the

274 mimicry is likely to involve both visual and olfactory signals, as pointed out in an earlier study (Vogel and Martens 275 2000).

276 As expected, the volatile compositions of A. sikokianum inflorescences chemically resembled those of 277 mushrooms (Figure $4 a$ and $b$ ). First, they were dominated by $\mathrm{C} 8$ aliphatics common among the fruiting bodies of 278 most of the fungal species examined, such as 3-octanone, 1-octene-3-ol and 1,3-octadiene. Moreover, they contained 279 some monoterpenes and sesquiterpenes in common with wood-decaying fungi, such as Ganorderma applanatum 280 (Tables 3 and S6), suggesting that the floral mimicry in A. sikokianum targets specific model fungal groups (e.g., some polypore fungi) rather than mushrooms in general.

The existence of mushroom mimicry in A. sikokianum was further supported by the striking similarity between

283 the assemblages of the floral visitors and insect communities attracted to some mushroom species (Figure 3b), both

284 of which were dominated by obligately mycophagous drosophilids (both males and females of Mycodrosophila

285 gratiosa and other Mycodrosophila species). Judging from their high visitation frequency of both male and female

286 inflorescences and ideal body size for effective pollination (see Materials and Methods), it is reasonable to identify

287 Mycodrosophila spp. as the principal pollinator of A. sikokianum. We further confirmed that mushroom-like

288 volatiles were emitted not only from the appendix but also from the spathe (Figure S1), and removal of the

289 mushroom-like appendix in the A. sikokianum inflorescence resulted in only a partial decrease in pollinator visits

290 without altering pollinator composition, which was dominated by Mycodrosophila. Note that the effect of appendix

291 removal was not visible in 2017, which had greater variance in data compared to 2019, likely because the

292 experiment was conducted later in the flowering season in 2017. Additionally, because we left the inflorescences of 
the control plants intact, our experimental design did not control for the wounding effect of appendix ablation.

294 Therefore, the mushroom mimicry apparatus in A. sikokianum is likely to be achieved by both the mushroom-like

295 appendix and the purple and white spathe.

296 Demonstrating pollination by floral mimicry is often challenging, since it requires an understanding of the

297 pollinators' perception without detailed knowledge of the life histories of hyperdiverse insects (especially dipterans).

298 For example, stable artificial breeding of Mycodrosophila spp. has not yet been established, hindering behavioral or

299 electrophysiological studies of the A. sikokianum-Mycodrosophila system. In this study, we demonstrated

300 mushroom mimicry in A. sikokianum by comparing the pollinator assemblage of $A$. sikokianum to the insect

301 communities attracted to various mushroom species in Japan. The latter data were available only because they were

302 collected previously by one of the authors (Tuno 2001). Although data on mushroom-attracted insect communities

303 were collected almost 20 years ago, their striking similarity to the pollinator assemblages of $A$. sikokianum supports

304 the idea that a deceptive pollination system exploiting mushroom-attracted insect communities could be ecologically

305 stable temporally and spatially. The present study therefore highlights the importance of quantitative data from local

306 community-based studies regarding the insects attracted to specific substrates, such as mushrooms, carrion and

307 animal feces, that are potentially mimicked by local plants.

\section{Mushroom mimicry in A. sikokianum as a possible unique Batesian food-source mimicry}

310 The mushroom mimicry system in A. sikokianum is apparently most comparable with that reported in the

311 neotropical orchids Dracula spp., which also exploit the mushroom-visiting behavior of mycophagous drosophilids

312 (Policha et al. 2016, 2019). In Dracula-drosophilid systems, the pollinators are never physically trapped by the

313 flowers and even receive some fitness benefits from the flowers, such as food, shelter, mating opportunities and, in

314 rare cases, breeding; thus, the pollination system is somewhat mutualistic rather than purely deceptive (Policha et al.

315 2019). Conversely, in A. sikokianum the pollinators are unlikely to receive any fitness benefits because the plant

316 species apparently lacks any floral reward, such as nectar, and even has a mechanism for imprisoning pollinators;

317 pollination success is always coupled with this reproductive dead end for the pollinators. It is also unlikely that male

318 inflorescences, from which the pollinators can escape, provide any fitness benefits to pollinators. This is because we

319 seldom encountered pollinators inside the intact male inflorescences, despite their fairly frequent visits, indicating

320 that the inflorescences do not provide any practical benefit that would retain pollinators. Therefore, the pollination

321 system of $A$. sikokianum may be unique in that it is an instance of purely deceptive mushroom mimicry.

322 Pollination by mushroom mimicry has often been discussed under the context of oviposition-site mimicry

323 (Johnson and Schiestl 2016), as some of the known examples of this pollination mode involve the oviposition

324 behavior of the pollinators (Vogel 1978, Sugawara 1988). However, based on our observations of Mycodrosophila

325 spp., the principal pollinator of A. sikokianum, did not lay eggs inside the spathe of A. sikokianum. Mycodrosophila

326 spp. visit fruiting bodies of some bracket fungi, such as Ganoderma applanatum, only to feed on spores on the

327 surface (Tuno 1999, Kobayashi et al. 2017), although fragmentary information suggests that they breed in the

328 fruiting bodies of other fungi (Kimura et al. 1977). Therefore, A. sikokianum likely exploits adult foraging behavior

329 rather than the oviposition of the pollinators, so it might be considered a special case of Batesian food-source

330 mimicry. 
We revealed that $A$. sikokianum has a pollinator assemblage distinct from other Arisaema spp., probably as a consequence of its unique visual and chemical mushroom mimicry traits. We are aware of at least 15 Arisaema spp. whose pollinators are known, but none are dominated by Drosophilidae pollinators or have typical mushroom mimicry traits (Vogel and Martens 2000, Nishizawa et al. 2005, Barriault et al. 2010, Tanaka et al. 2013, Kakishima and Okuyama 2018). We further confirmed that floral volatile profiles of the other Arisaema spp. that are potentially sympatric to A. sikokianum, including A. japonicum, bore no resemblance to those of mushrooms (Figure 4c). These results indicate that mushroom mimicry is unusual within this genus, although this view seems somewhat contradictory with traditional views on Arisaema pollination.

Mushroom mimicry has long been suggested as a pollination mechanism for this genus (Vogel and Martens 2000), since most reported pollinators for Arisaema spp., and for A. japonicum in the present study, are fungus gnats (Sciaridae and Mycetophilidae) (Sasakawa 1993, 1994a, b, Vogel and Martens 2000). Fungus gnats are often reported to be mycophagous in their larval stage (but see Freeman 1983 and Okuyama et al. 2018 for a discussion of herbivory among these insects). However, several studies have shown that adult fungus gnats often feed on nectar from flowers (Ackerman and Mesler 1979, Okuyama et al. 2004, 2008), suggesting that some volatile signals such as monoterpenes (e.g., linalool and its derivatives in Mitella spp.) (Okamoto et al. 2015) may attract these insects, as well as visual signals such as the greenish or reddish color (Mochizuki and Kawakita 2017) of fungus-gnat-visited flowers. By contrast, Mycodrosophila spp., the principal pollinator of A. sikokianum, never visit flowers for nectar, whereas both male and female flies visit various mushrooms for courtship semaphoring, food, shelter, territory defense and mating (Policha et al. 2019). Collectively, these observations imply that the mushroom mimicry in $A$. sikokianum is derived from Batesian food-source mimicry involving fungus, which might be prevalent in the genus Arisaema.

It is noteworthy that pollination via mushroom mimicry in A. sikokianum likely functions as an efficient reproductive barrier from other sympatric, closely-related Arisaema spp. such as A. japonicum, because there is little overlap between them in pollinator assemblages Matsumoto et al. (in press) also demonstrated strong pollinator isolation between A. sikokianum and A. tosaense in their sympatric populations. Accordingly, it is possible that the evolutionary acquisition of mushroom mimicry traits in the A. sikokianum lineage coincided with ecological speciation, as most species of genus Arisaema section Pistillata, including A. sikokianum, are cross-compatible based on extensive artificial cross experiments (Murata et al. 2018). Although the species most closely related to $A$. sikokianum is currently unknown, it is clear that the speciation event took place very recently, since a recent phylogenetic study of the genus using $\sim 2.8 \mathrm{~kb}$ chloroplast DNA found little genetic variation among $31 \mathrm{spp}$., including A. sikokianum, belonging to the same section (Pistillata) (Ohi-Toma et al. 2016). Future comparative studies between A. sikokianum and its sister species in the fields of ecology, genetics or physiology may provide an excellent opportunity to study the mechanisms of coordinated acquisition of elaborate mushroom mimicry traits, and to test the hypothesis of ecological speciation associated with mushroom mimicry, which is one of the most bizarre

367 phenomena in floral evolution. 
The authors thank Masanori Toda for the identification of drosophilids, Hiroko Murata for the living material of Arisaema yamatense, and Chiemi Takaboshi and Yumiko Suzuki for supporting the DNA barcoding of pollinators. We also thank the anonymous reviewers for their helpful comments on an earlier draft of the manuscript. This work was supported by JSPS KAKENHI Grant Numbers $15 \mathrm{H} 05604$ and $19 \mathrm{H} 03292$, and the $28^{\text {th }}$ Botanical Research Grant of the ICHIMURA Foundation For New Technology (to Y.O.). We certify that the present research was conducted in conformance with all applicable laws regarding the endangered species (A. sikokianum).

Ackerman, J. D., and M. R. Mesler. 1979. Pollination biology of Listera cordata (Orchidaceae). American Journal of Botany 66: 820-824. (doi:10.1002/j.1537-2197.1979.tb06288.x)

Barriault, I., D. Barabé, L. Cloutier, and M. Gibernau. 2010 Pollination ecology and reproductive success in Jack-inthe-pulpit (Arisaema triphyllum) in Québec (Canada). Plant Biology 12: 161-171. (doi:10.1111/j.14388677.2009.00192.x)

Bates, D., M. Mächler, B. Bolker, and S. Walker. 2015. Fitting linear mixed-effects models using lme4. Journal of Statistical Software 67. (doi:10.18637/jss.v067.101)

Cox, P. A. 1991. Abiotic pollination: an evolutionary escape for animal-pollinated angiosperms. Philosophical Transactions of the Royal Society B: Biological Sciences 333: 217-224. (doi:10.1098/rstb.1991.0070)

Culley, T. M., S. G. Weller, and A. K. Sakai. 2002. The evolution of wind pollination in angiosperms. Trends in Ecology and Evolution 17: 361-369.

Endara, L., D. Grimaldi, and B. Roy. 2010. Lord of the flies: pollination of Dracula orchids. Lankesteriana 10: 111. (doi:10.15517/lank.v10i1.18318)

Fenster, C. B., W. S. Armbruster, P. Wilson, M. R. Dudash, and J. D. Thomson. 2004. Pollination syndromes and floral specialization. Annual Reviews of Ecology, Evolution, and Systematics 35: 375-403. (doi: 10.1146/annurev.ecolsys.34.011802.132347)

Freeman, P. 1983. Sciarid flies. Diptera, Sciaridae. Handbooks for the Identification of British Insects 9, 6. St Albans, UK: Royal Entomological Society.

Friberg, M., C. Schwind, R. A. Raguso, and J. N. Thompson. 2013. Extreme divergence in floral scent among woodland star species (Lithophragma spp.) pollinated by floral parasites. Annals of Botany 111: 539-550.

Fukai, S. 2004 Floral initiation and development of the sex-changing plant Arisaema sikokianum (Araceae). International Journal of Plant Sciences 165: 739-744. (doi:10.1086/422051)

Hanski, I. 1989. Fungivory: fungi, insects and ecology. In Insect-fungus interactions. (eds M Wilding, MM Collins, PM Hammond, JF Webber), pp. 25-68. London, UK: Academic Press. (doi:10.1016/B978-0-12-7518008.50008-2)

Jersáková, J., S. D. Johnson, and P. Kindlmann. 2006. Mechanisms and evolution of deceptive pollination in orchids. Biological Reviews 81: 219-235. (doi:10.1017/S1464793105006986) (doi:10.1093/acprof:oso/9780198732693.001.0001) 
Kakishima, S., and Y. Okuyama. 2018. Pollinator assemblages of Arisaema heterocephalum subsp. majus (Araceae), a critically endangered species endemic to Tokunoshima island, central Ryukyus. Bulletin of the National Museum of Nature and Science, Series B, Botany 44: 173-179.

Kimura, M. T., M. J. Toda, K. Beppu, and H. Watabe. 1977. Breeding sites of drosophilid flies in and near Sapporo, Northern Japan, with supplementary notes on adult feeding habits. Konchu 45: 571-582.

Kobayashi, M., K. Kitabayashi, and N. Tuno. 2017. Spore dissemination by mycophagous adult drosophilids. Ecological Research 32: 621-626. (doi:10.1007/s11284-017-1477-9)

Lacy, R. C. 1984. Predictability, toxicity, and trophic niche breadth in fungus-feeding Drosophilidae (Diptera). Ecological Entomology 9: 43-54. (doi:10.1111/j.1365-2311.1984.tb00697.x)

Linstrom, P. J., and W. G. Mallard. 2001. The NIST Chemistry WebBook: A chemical data resource on the internet. Journal of Chemical \& Engineering Data 46: 1059-1063. (doi:10.1021/je000236i)

Matsumoto, T. K., Y. Miyazaki, M. Sueyoshi, Y. Senda, K. Yamada, and M. Hirobe. Pre-pollination isolating barriers between two sympatric Arisaema species in northern Shikoku Island, Japan. American Journal of Botany. In press.

Ministry of the Environment Government of Japan. 2012. The Red List of Vascular Plants of Japan. (https://www.env.go.jp/press/file_view.php? serial=20557andhou_id=15619) (accessed 10.07.19.).

Mochizuki, K., and A. Kawakita. 2017. Pollination by fungus gnats and associated floral characteristics in five families of the Japanese flora. Annals of Botany 121: 651-663. (doi:10.1093/aob/mcx196)

Murata J, J. Ohno, T. Kobayashi, and T. Ohi-Toma. 2018. The genus Arisaema in Japan. Tokyo, Japan: Hokuryukan.

Nishizawa, T., Y. Watano, E. Kinoshita, T. Kawahara, and K. Ueda. 2005. Pollen movement in a natural population of Arisaema serratum (Araceae), a plant with a pitfall-trap flower pollination system. American Journal of Botany 92: 1114-1123. (doi:10.3732/ajb.92.7.1114)

O’Grady, P. M., and R. DeSalle. 2018. Phylogeny of the genus Drosophila. Genetics 209: 1-25. (doi:10.1534/genetics.117.300583)

Ohi-Toma, T., S. Wu, H. Murata, and J. Murata. 2016. An updated genus-wide phylogenetic analysis of Arisaema (Araceae) with reference to sections. Botanical Journal of the Linnean Society 182: 100-114. (doi:10.1111/boj.12459)

Okamoto, T., Y. Okuyama, R. Goto, M. Tokoro, and M. Kato. 2015 Parallel chemical switches underlying pollinator isolation in Asian Mitella. Journal of Evolutionary Biology 28: 590-600.

Oksanen, J., F. G. Blanchet, M. Friendly, R. Kindt, P. Legendre, D. McGlinn, P. R. Minchin, R. B. O’Hara, G. L. Sympson, P. Solymos, M. H. H. Stevens, E. Szoecs, and H. Wagner. 2016. vegan: Community Ecology Package. R package, Version 2.4-0. (https://github.com/vegandevs/vegan)

Okuyama, Y., M. Kato, and N. Murakami. 2004. Pollination by fungus gnats in four species of the genus Mitella (Saxifragaceae). Botanical Journal of the Linnean Society 144: 449-460. (doi:10.1111/j.10958339.2003.00259.x)

Okuyama, Y., O. Pellmyr, and M. Kato. 2008. Parallel floral adaptations to pollination by fungus gnats within the genus Mitella (Saxifragaceae). Molecular Phylogenetics and Evolution 46: 560-575. (doi:10.1016/j.ympev.2007.09.020) 
Okuyama, Y., T. Okamoto, J. Kjærandsen, and M. Kato. 2018. Bryophytes facilitate outcrossing of Mitella by functioning as larval food for pollinating fungus gnats. Ecology 99: 1890-1893. (doi:10.1002/ecy.2364)

Ollerton, J., R. Alarcón, N. M. Waser, M. V. Price, S. Watts, L. Cranmer, A. Hingston, C. I. Peter, and J. Rotenberry. 2009. A global test of the pollination syndrome hypothesis. Annals of Botany 103: 1471-1480. (doi:10.1093/aob/mcp031)

Policha, T., A. Davis, M. Barnadas, B. Dentinger, R. A. Raguso, and B. A. Roy. 2016. Disentangling visual and olfactory signals in mushroom-mimicking Dracula orchids using realistic three-dimensional printed flowers. New Phytologist 210: 1058-1071. (doi:10.1111/nph.13855)

Policha, T, D. A. Grimaldi, R. Manobanda, A. Troya, A. Ludden, B. T. Dentinger, and B. A. Roy. 2019. Dracula orchids exploit guilds of fungus visiting flies: new perspectives on a mushroom mimic. Ecological Entomology 44: 457-470. (doi:10.1111/een.12720)

Povolo, M., and G. Contarini. 2003. Comparison of solid-phase microextraction and purge-and-trap methods for the analysis of the volatile fraction of butter. Journal of Chromatography A 985: 117-125.

Renner, S. S. 2006. Rewardless flowers in the angiosperms and the role of insect cognition in their evolution. In Plant-pollinator interactions: from specialization to generalization. (ed. NM Waser) pp.123-144. Chicago, IL: University of Chicago Press.

Sasakawa, M. 1993. Fungus gnats associated with flowers of the genus Arisaema (Araceae). Japanese Journal of Entomology 61: 783-786.

Sasakawa, M. 1994a. Fungus gnats associated with flowers of the genus Arisaema (Araceae). part 2. Keroplatidae and Mycetophilidae (Diptera). Transactions of the Shikoku Entomological Society 20: 293-306.

Sasakawa, M. 1994b. Fungus gnats associated with flowers of the genus Arisaema (Araceae): part 3. Sciaridae (Diptera). Konchu 62: 667-681.

Scopece, G., S. Cozzolino, S. D. Johnson, and F. P. Schiestl. 2009. Pollination efficiency and the evolution of specialized deceptive pollination systems. The American Naturalist 175: 98-105.

472 Suetsugu, K. 2018. Achlorophyllous orchid can utilize fungi not only for nutritional demands but also pollinator attraction. Ecology 99: 1498-1500. (doi:10.1002/ecy.2170)

Sugawara, T. 1988. Floral biology of Heterotropa tamaensis (Aristolochiaceae) in Japan. Plant Sp. Biol. 3, 7-12. (doi:10.1111/j.1442-1984.1988.tb00166.x)

Tanaka, N, M. Sasakawa, and J. Murata. 2013. Pollinators of Arisaema thunbergii subsp. urashima (Araceae) in Japan. Bulletin of the National Museum of Nature and Science, Series B, Botany 39: 21-24.

478 Tuno, N. 1999. Insect feeding on spores of a bracket fungus, Elfvingia applanata (Pers.) Karst. (Ganodermataceae, Aphyllophorales). Ecological Research 14: 97-103. (doi: 10.1046/j.1440-1703.1999.00290.x)

Tuno, N. 2001. The community structure of mycophagous insects in Kyoto, central Japan. Japanese Journal of Ecology 51: 73-86. (doi:10.18960/seitai.51.2_73)

482 Venables, W. N., and B. D. Ripley. 2002. Modern applied statistics with S. New York, NY: Springer.

483 Vogel, S. 1978. Pilzmückenblumen als Pilzmimeten. Flora 167: 329-398. (doi:10.1016/S0367-2530(17)31124-6)

484 Vogel, S., and J. Martens. 2000. A survey of the function of the lethal kettle traps of Arisaema (Araceae), with 485 records of pollinating fungus gnats from Nepal. Botanical Journal of the Linnean Society 133: 61-100. (doi: 10.1006/bojl.1999.0317) 
Table 1. Pollinator visitation frequency to male inflorescences of $A$. sikokianum and A.japonicum across study sites and years.

\begin{tabular}{|c|c|c|c|c|c|c|}
\hline Species & Year & Site & $\begin{array}{l}\text { No. of } \\
\text { inflorescences }\end{array}$ & Pollinator visits & $\begin{array}{l}\text { Visits per } \\
\text { inflorescence }\end{array}$ & $\begin{array}{l}\text { Visits per } \\
\text { inflorescence } \\
\text { per day }\end{array}$ \\
\hline \multirow[t]{6}{*}{ A. sikokianum } & \multirow[t]{3}{*}{2017} & 1 & 10 & 32 & $3.20 \pm 3.26$ & 1.60 \\
\hline & & 2 & $15^{*}$ & 39 & $2.60 \pm 4.44$ & 1.30 \\
\hline & & total & 25 & 71 & $2.84 \pm 3.94$ & 1.42 \\
\hline & \multirow[t]{3}{*}{2018} & 1 & 6 & 12 & $2.00 \pm 1.67$ & 1.00 \\
\hline & & 2 & 15 & 36 & $2.40 \pm 1.72$ & 1.20 \\
\hline & & total & 21 & 48 & $2.29 \pm 1.68$ & 1.14 \\
\hline \multirow[t]{6}{*}{ A.japonicum } & \multirow[t]{3}{*}{2017} & 1 & 22 & 15 & $0.68 \pm 0.99$ & 0.34 \\
\hline & & 2 & 15 & 7 & $0.47 \pm 0.83$ & 0.23 \\
\hline & & total & 37 & 22 & $0.59 \pm 0.93$ & 0.30 \\
\hline & \multirow[t]{3}{*}{2018} & 1 & 26 & 46 & $1.77 \pm 2.39$ & 0.88 \\
\hline & & 2 & 8 & 3 & $0.38 \pm 0.52$ & 0.19 \\
\hline & & total & 34 & 49 & $1.44 \pm 2.18$ & 0.72 \\
\hline
\end{tabular}

*Only a subset of inflorescences was used for identification of pollinators. 
Table 2. Effects of appendix removal on pollinator visit frequency to A. sikokianum.

\begin{tabular}{|c|c|c|c|c|c|c|c|}
\hline Treatment & Year & Site & Study period & $\begin{array}{l}\text { No. of } \\
\text { inflorescences }\end{array}$ & $\begin{array}{l}\text { Pollinator } \\
\text { visits }\end{array}$ & $\begin{array}{l}\text { Visits per } \\
\text { inflorescence }\end{array}$ & $\begin{array}{l}\text { Visits per } \\
\text { inflorescence } \\
\text { per day }\end{array}$ \\
\hline \multirow[t]{4}{*}{ Control } & 2017 & 2 & 23-25 Apr & 15 & 39 & $2.60 \pm 4.44$ & 1.30 \\
\hline & 2019 & 1 & 11-13 Apr & 7 & 18 & $2.57 \pm 2.23$ & 1.29 \\
\hline & & 2 & 12-13 Apr & 20 & 35 & $1.75 \pm 1.71$ & 1.75 \\
\hline & total & & & 42 & 92 & $2.19 \pm 3.01$ & 1.51 \\
\hline \multirow[t]{4}{*}{ Removal } & 2017 & 2 & 23-25 Apr & 15 & 39 & $2.60 \pm 2.56$ & 1.30 \\
\hline & 2019 & 1 & 11-13 Apr & 9 & 9 & $1.00 \pm 1.32$ & 0.50 \\
\hline & & 2 & 12-13 Apr & 21 & 13 & $0.62 \pm 0.86$ & 0.62 \\
\hline & total & & & 45 & 61 & $1.36 \pm 1.88$ & 0.82 \\
\hline
\end{tabular}


Table 3. Representative volatile compounds detected in inflorescences of Arisaema sikokianum and A. japonica and fruiting bodies of Ganoderma applanatum. Percentages of the total ion chromatogram peak area are shown, from data averaged among individual samples for each category. The full dataset is provided in Table S6.

\begin{tabular}{|c|c|c|c|c|c|c|c|c|}
\hline Name & RI & $\begin{array}{l}\text { Peak } \\
\text { No. in } \\
\text { Figure } 4\end{array}$ & $\begin{array}{l}\text { Identifi- } \\
\text { cation* }\end{array}$ & $\begin{array}{l}\text { Arisaema } \\
\text { sikokianum } \\
\text { male }(\mathrm{N}=3)\end{array}$ & $\begin{array}{l}\text { Arisaema } \\
\text { sikokianum } \\
\text { female } \\
(\mathrm{N}=6)\end{array}$ & $\begin{array}{l}\text { Arisaema } \\
\text { japonicum } \\
\text { male } \\
(\mathrm{N}=6)\end{array}$ & $\begin{array}{l}\text { Arisaema } \\
\text { japonicum } \\
\text { female } \\
(\mathrm{N}=2)\end{array}$ & $\begin{array}{l}\text { Ganoderma } \\
\text { applanatum } \\
(\mathrm{N}=2)\end{array}$ \\
\hline \multicolumn{9}{|l|}{ C8 aliphatics and derivatives } \\
\hline 1-Octene & 779 & 1 & A & - & - & - & - & $4.1 \pm 3.8$ \\
\hline 1-Octen-3-one & 975 & 4 & A & - & - & - & - & $6.2 \pm 0.1$ \\
\hline 1-Octen-3-ol & 982 & 5 & A & $1.7 \pm 1.5$ & $0.6 \pm 0.4$ & - & - & $39.1 \pm 6.1$ \\
\hline 3-Octanone & 987 & 6 & A & $27.1 \pm 11.9$ & $21.5 \pm 8.6$ & - & - & $23.5 \pm 5.0$ \\
\hline 3-Octanol & 998 & 8 & A & $\operatorname{tr}$ & $0.1 \pm 0.2$ & - & $0.7 \pm 0.9$ & $4.8 \pm 3.8$ \\
\hline trans 2-Octen-1-ol & 1068 & 10 & A & - & - & - & - & $0.5 \pm 0.2$ \\
\hline 1-Octen-3-yl, acetate & 1108 & 12 & B & $0.7 \pm 0.8$ & $0.3 \pm 0.3$ & - & - & $0.3 \pm 0.4$ \\
\hline 3-Octanol, acetate & 1120 & 13 & B & - & $\operatorname{tr}$ & - & - & $0.2 \pm 0.2$ \\
\hline $\begin{array}{l}\text { Acetic acid, 2-ethylhexyl } \\
\text { ester }\end{array}$ & 1147 & 15 & A & $2.8 \pm 2.9$ & $2.0 \pm 2.0$ & - & - & - \\
\hline \multicolumn{9}{|l|}{ Monoterpenes } \\
\hline$\alpha$-Pinene & 930 & 2 & A & $0.6 \pm 0.6$ & $0.8 \pm 0.4$ & $54.8 \pm 27.3$ & $47.9 \pm 40.3$ & - \\
\hline$\beta$-Pinene & 974 & 3 & A & $0.7 \pm 0.1$ & $0.7 \pm 0.4$ & $2.2 \pm 3.6$ & $1.2 \pm 1.6$ & - \\
\hline$\beta$-Myrcene & 989 & 7 & A & $1.3 \pm 1.2$ & $1.8 \pm 1.2$ & $3.3 \pm 2.8$ & - & - \\
\hline Limonene & 1027 & 9 & A & $0.2 \pm 0.2$ & $0.6 \pm 0.6$ & $6.7 \pm 7.1$ & $5.9 \pm 5.1$ & $\operatorname{tr}$ \\
\hline Linalool & 1098 & 11 & A & $0.1 \pm 0.1$ & $0.1 \pm 0.3$ & - & - & $0.1 \pm 0.2$ \\
\hline \multicolumn{9}{|l|}{ Sesquiterpenes } \\
\hline Elemene isomer 2 & 1334 & 16 & $\mathrm{C}$ & $1.2 \pm 1.7$ & $2.1 \pm 0.9$ & - & - & - \\
\hline$\alpha$-Cubebene & 1346 & 17 & B & $1.7 \pm 2.3$ & $3.7 \pm 2.1$ & - & - & $1.6 \pm 2.2$ \\
\hline$\alpha$-Copaene & 1375 & 18 & B & $1.3 \pm 1.7$ & $2.5 \pm 1.0$ & - & - & $0.3 \pm 0.1$ \\
\hline $\begin{array}{l}\text { Unidentified } \\
\text { sesquiterpene } 15\end{array}$ & 1386 & 19 & & $1.8 \pm 2.5$ & $5.0 \pm 2.6$ & - & - & $2.4 \pm 3.3$ \\
\hline $\begin{array}{l}\text { Unidentified } \\
\text { sesquiterpene } 16\end{array}$ & 1388 & 20 & & $1.4 \pm 1.4$ & $0.2 \pm 0.6$ & - & - & - \\
\hline$\alpha$-Barbatene & 1412 & 21 & B & - & - & - & - & $0.4 \pm 0.6$ \\
\hline $\begin{array}{l}\text { Unidentified } \\
\text { sesquiterpene } 24\end{array}$ & 1426 & 22 & & $12.1 \pm 1.6$ & $7.2 \pm 4.3$ & - & - & - \\
\hline$\beta$-Barbatene & 1447 & 23 & B & - & - & - & - & $3.3 \pm 4.7$ \\
\hline $\begin{array}{l}\text { Unidentified } \\
\text { sesquiterpene } 38\end{array}$ & 1471 & 24 & & $2.1 \pm 0.3$ & $1.6 \pm 0.8$ & - & - & - \\
\hline$\gamma$-Muurolene & 1474 & 25 & B & $1.3 \pm 0.9$ & $1.4 \pm 0.7$ & - & - & $0.1 \pm 0.2$ \\
\hline $\begin{array}{l}\text { Unidentified } \\
\text { sesquiterpene } 44\end{array}$ & 1490 & 26 & & $0.4 \pm 0.5$ & $0.7 \pm 0.3$ & - & - & $0.2 \pm 0.2$ \\
\hline$\delta$-Cadinene & 1517 & 27 & B & $0.6 \pm 0.9$ & $1.3 \pm 0.6$ & - & - & $0.4 \pm 0.6$ \\
\hline Dauca-4(11),8-diene & 1527 & 28 & B & $4.6 \pm 4.1$ & $5.7 \pm 4.2$ & - & $2.3 \pm 3.3$ & $0.1 \pm 0.2$ \\
\hline Cadina-1(2),4-diene & 1531 & 29 & B & $0.9 \pm 1.3$ & $1.7 \pm 0.6$ & - & - & $0.3 \pm 0.4$ \\
\hline Carotol & 1601 & 30 & B & $0.5 \pm 0.1$ & $0.3 \pm 0.2$ & - & - & - \\
\hline \multicolumn{9}{|l|}{ Other compound } \\
\hline Benzyl nitrile & 1133 & 14 & $\mathrm{~B}$ & $17.6 \pm 19.0$ & $12.7 \pm 15.1$ & - & - & - \\
\hline
\end{tabular}

*Identification of compounds was based on A: mass spectrum and retention index of the authentic compound, and B: similarity of the mass spectrum to those in libraries and RI index values reported in the NIST Chemistry WebBook. For peaks marked C, identification was based solely on similarity of the mass spectrum to those in libraries, and this category can therefore be regarded as a preliminary identification. 

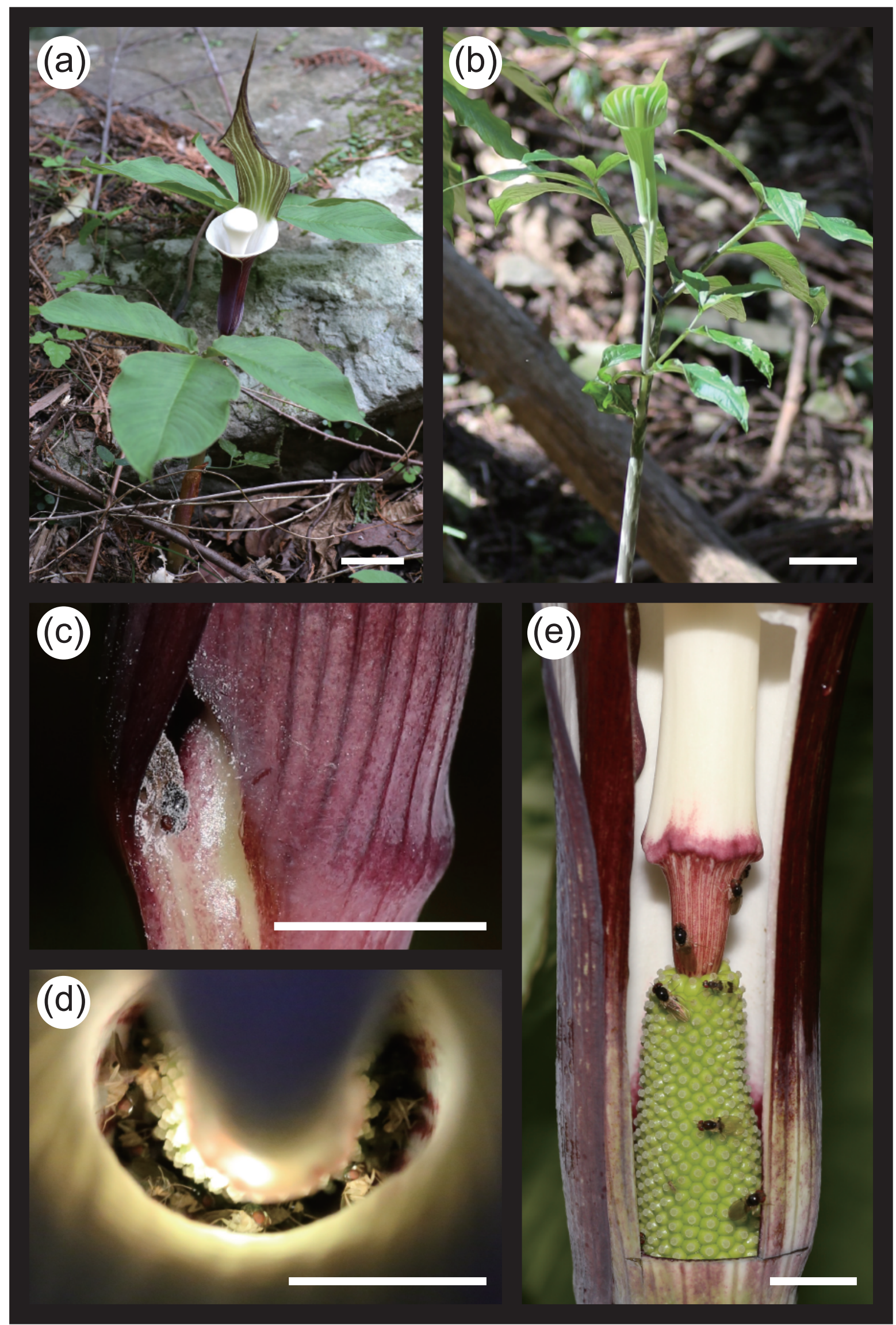

Figure 1. The flowering Arisaema spp. at the study sites. (a) A. sikokianum. (b) A. japonicum. (c) Mycodrosophila sp. escaping from the bottom exit hole of the male inflorescence of A. sikokianum. (d) Pollinators imprisoned in the female inflorescence of A. sikokianum, as visible from the top. (e) Pollinators imprisoned in the female inflorescence of $A$. sikokianum, as visible from the side after removal of the spathe. Scale $=5 \mathrm{~cm}$ (a and $\mathrm{b}$ ) and $1 \mathrm{~cm}(\mathrm{c}-\mathrm{e})$. 


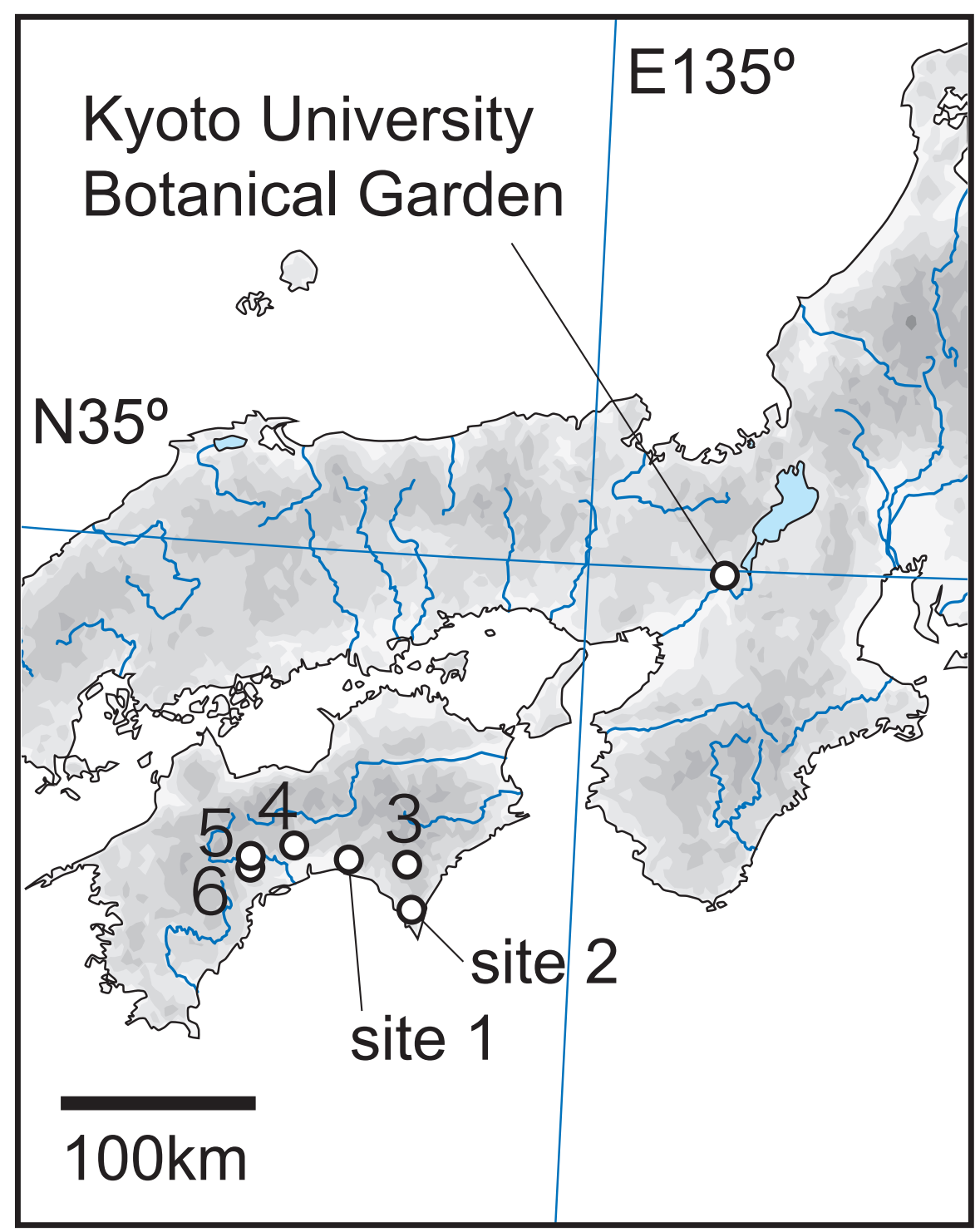

Figure. 2. The location of the six field study sites and Kyoto University Botanical Garden. 
(a)

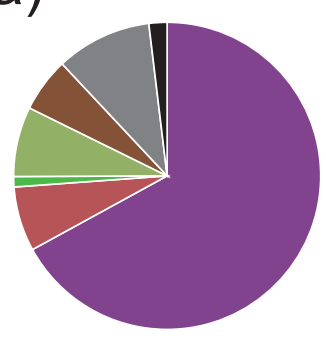

A. sikokianum

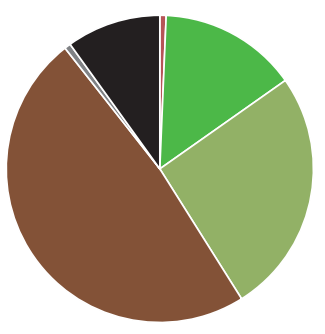

A. japonicum

$\mathrm{N}=151$

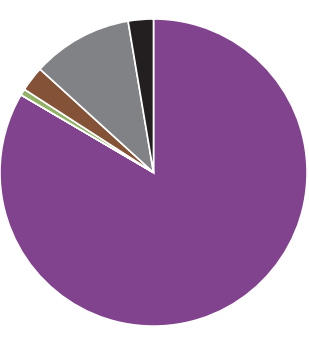

G. applanatum

(bracket fungus)

$\mathrm{N}=151$
Mycodrosophila

Other Drosophilidae

Mycetophilidae

Sciaridae

Other Diptera

Coleoptera

Other insects

(b)

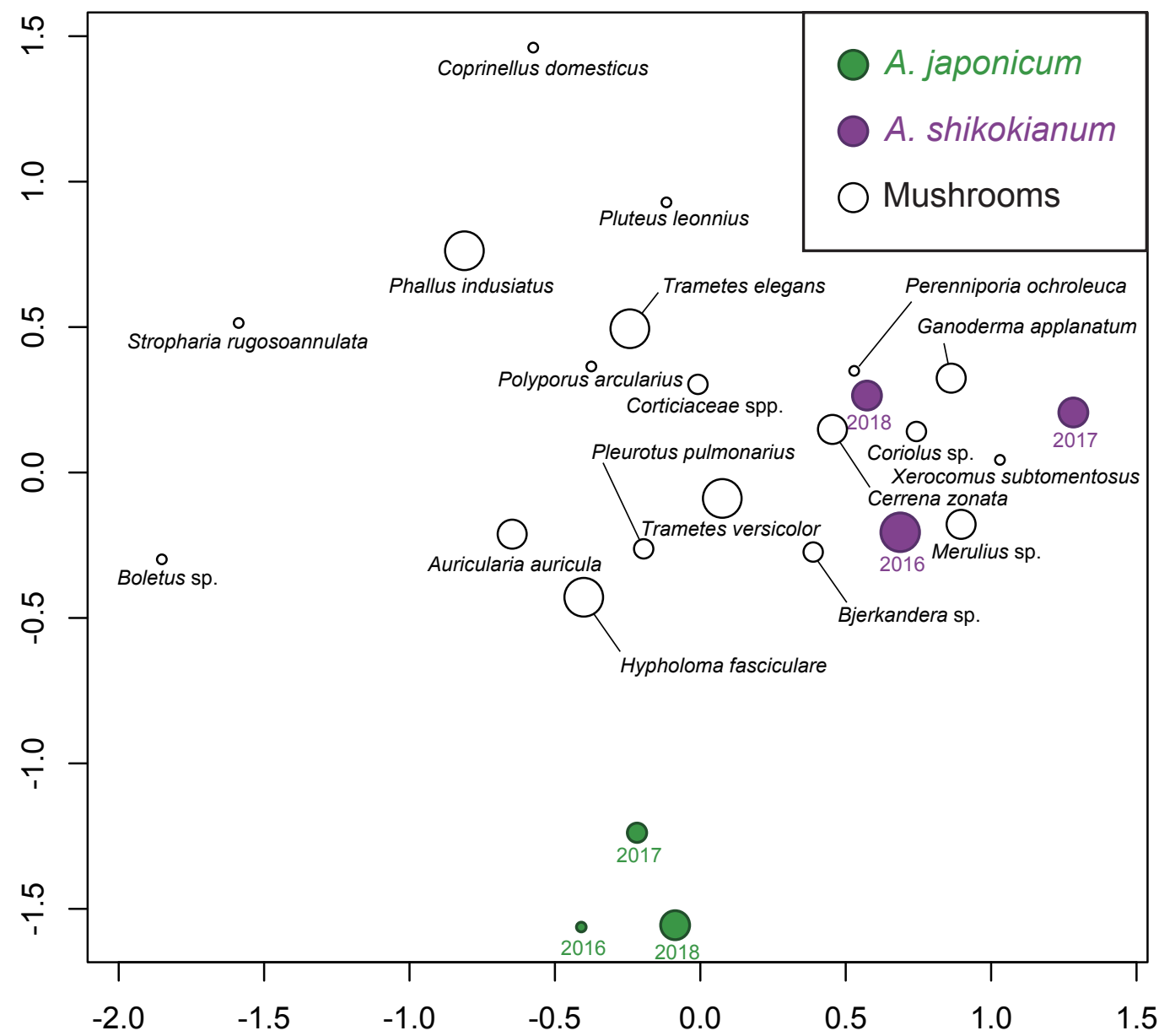

Figure 3. The insect assemblages that visited the inflorescences of Arisaema spp. and the various mushrooms. (a) Categories of insect species trapped inside the spathes of A. sikokianum and $A$. japonicum and those visiting the fruiting bodies of the bracket fungus Ganorderma applanatum illustrated as pie charts. (b) Nonmetric multidimensional ordination plot of the insect assemblages. The size of the plots corresponds to the sampling size (four levels: $\mathrm{N}<40, \mathrm{~N}<80, \mathrm{~N}<160$, and $\mathrm{N}>160$, respectively). The individual plots for Arisaema spp. correspond to the study years (2016-2018). 
(a)

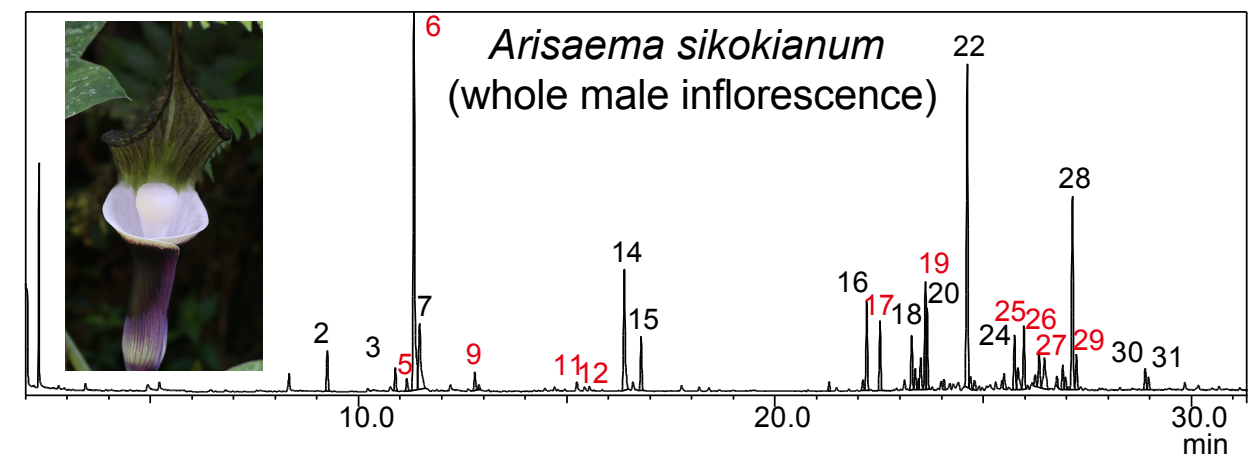

(b)

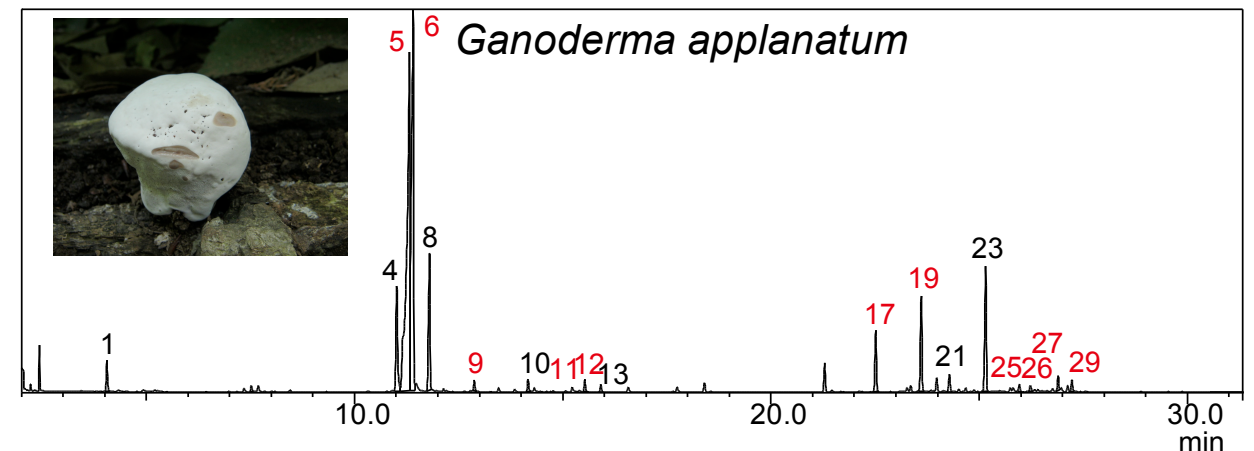

(c)

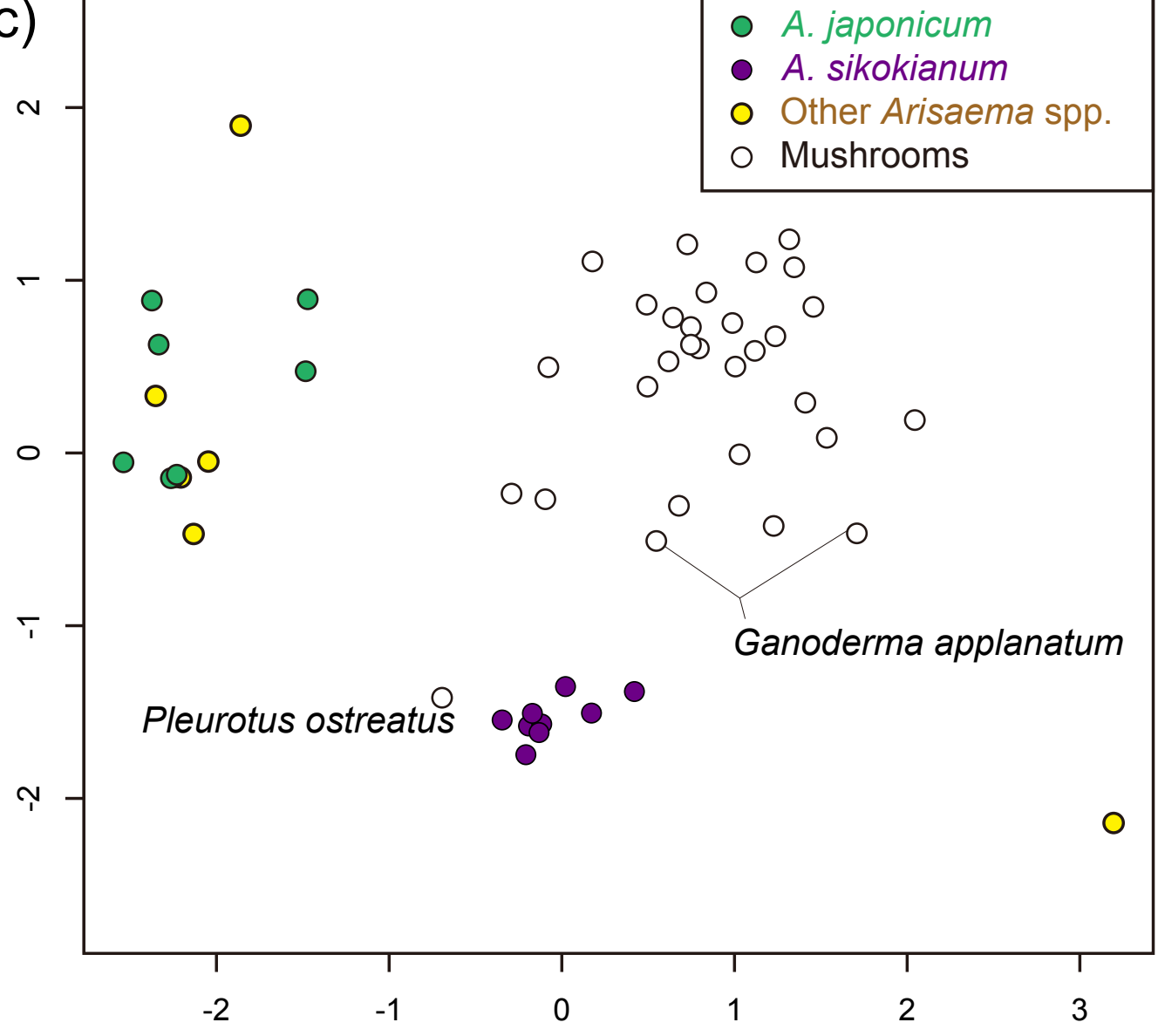

Figure 4. The volatile compositions of Arisaema spp. and the various mushrooms. (a and b) The total ion chromatogram of an inflorescence of A. sikokianum (a) and a fruiting body of Ganoderma applanatum (b). Only the principal compounds are shown with peak numbers, and the compounds in common between the two samples are shown in red. The peak numbers correspond to those shown in Table 3. (c) The nonmetric multidimensional ordination plot of the volatile compositions from samples of Arisaema spp. and various mushrooms. One Arisaema sample (A. angustatum 166181) was not included in the ordination analysis because it is extremely dissimilar to the other samples. A. sikokianum, A. japonicum, the other Arisaema spp., and the mushrooms are colored purple, green, yellow, and white, respectively. 
(a)

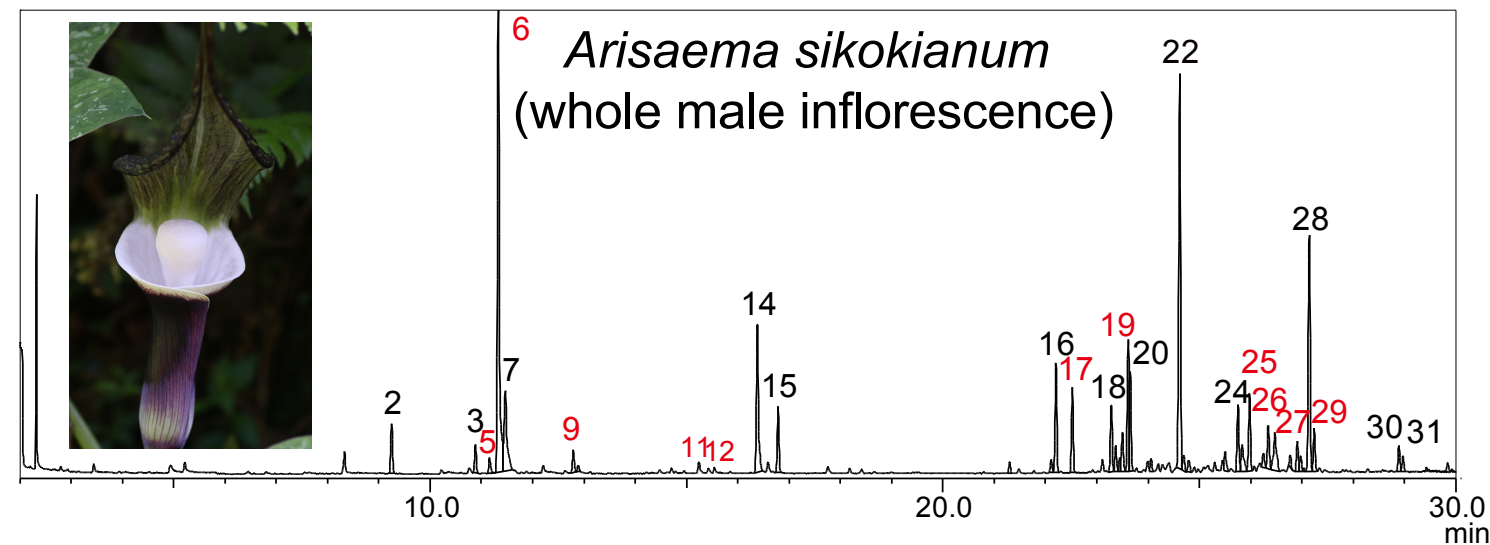

(b)

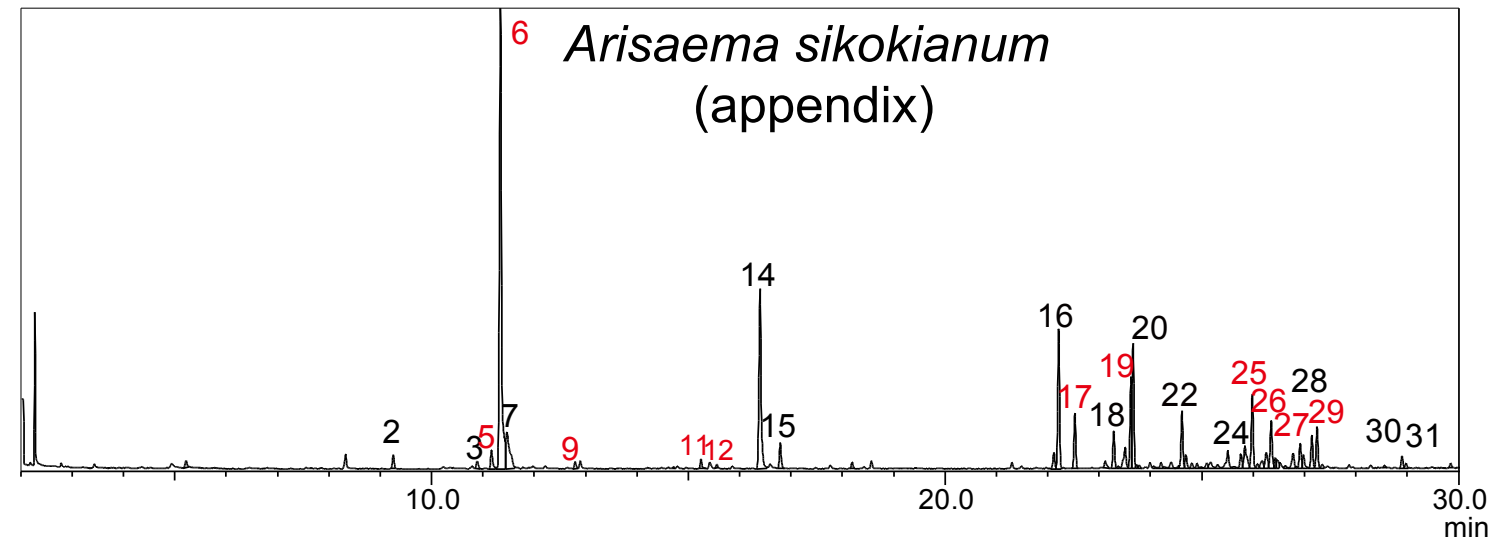

(c)

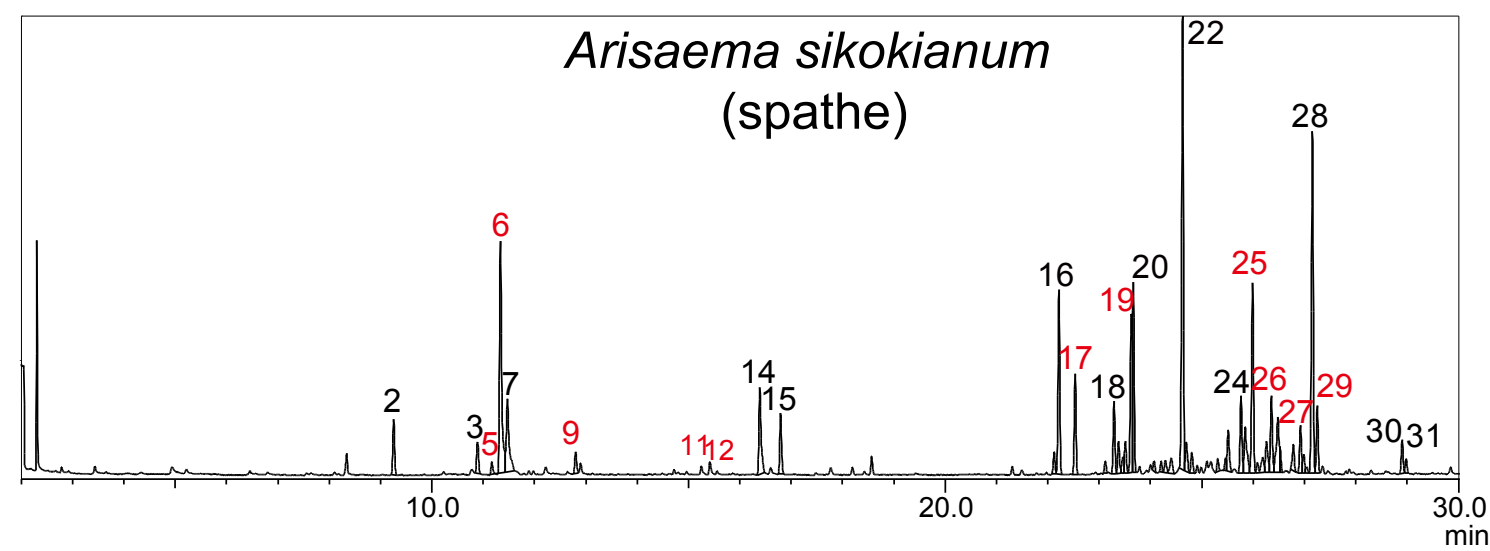

(d)

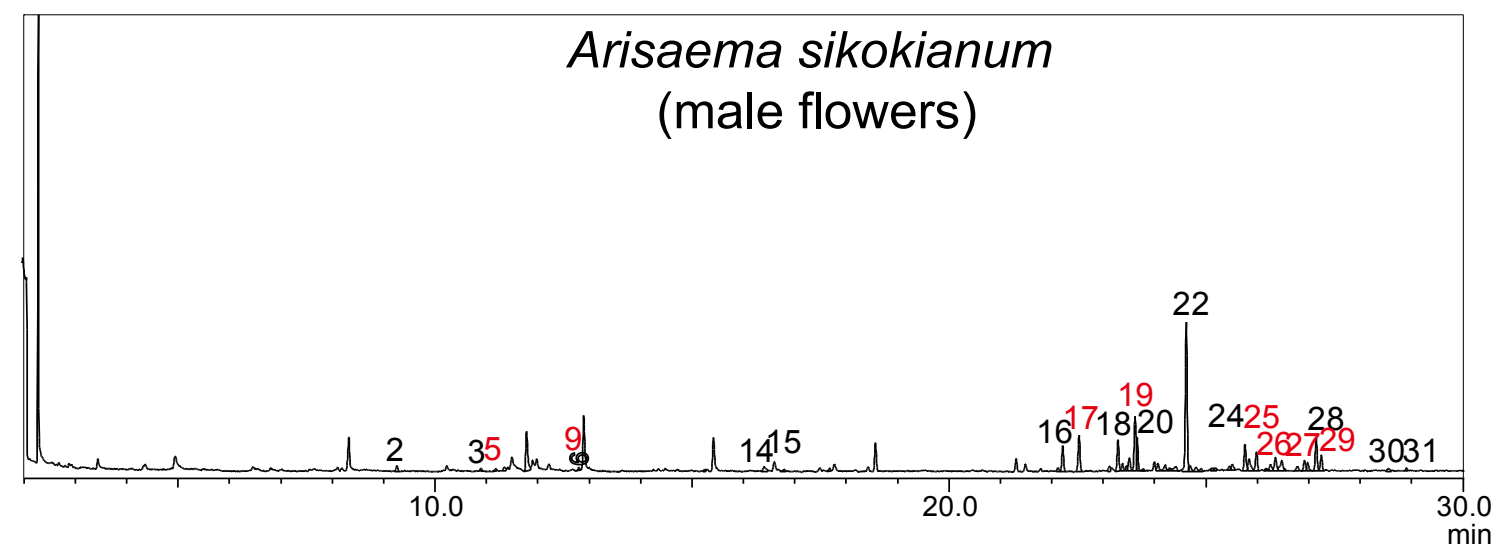

Figure S1. The total ion chromatogram of an inflorescence of $A$. sikokianum analyzed separately in different parts. (a) Whole inflorescence (the same chromatogram as in Fig. 4. a). (b) Appendix. (c) Spathe. (d) Male flower cluster. 